\title{
Pênfigo foliáceo em um gato de oito meses de idade: possível reação cutânea adversa a fármacos?
}

\author{
Pemphigus Foliaceus in an Eight-month-old Cat: Possible Cutaneous Adverse Drug Reaction? \\ Camila Gottlieb Lupion, Eloisa Helena Moreira Pino, Elissandra da Silveira, \\ Carine Ribas Stefanello, Leticia Talita Baretta \& Daniel Guimarães Gerardi
}

\begin{abstract}
Background: Pemphigus foliaceus is an autoimmune skin disease whose the occurrence in feline clinic is uncommom. The etiology is unknown in most cases. Althought it is a rare condition in cats, pemphigus foliaceus can be induced by drugs. It may affect both adult and old cats with no sexual or racial predilection and diagnosis is based on animal historical, clinical examination and skin histopathology. Moreover, the treatment consists in immunosuppressive-based drugs. This paper describes a pemphigus foliaceus case in an eight-month-old kitten, probably due a cutaneous adverse drug reaction. Case: A 8-month-old, neutered male mongrel cat with crusted lesions located on face was examinated at the Veterinary Hospital. The owners reported that they had adopted the patient two months before the clinical presentation suggesting that this background was unknown. The cat was treated in a local veterinary clinic with antibiotics and anti-inflammatory for rhinotracheitis and herpetic dermatitis on face due to the occurrence of sneezing and crusted pruriginous dermatitis. The kitten presented erosions, purulent exudation and crusts on pinnae, nasal and supra ocular areas, paronychia with purulent exudate and alopecia at distal portion of the tail. Supplementary exams such as skin scraping, cytology and fungal culture were performed to rule out other agents and confirm the diagnosis. The parasitological and fungal examination resulted negative despite the fact that cytological exam showed coccoid bacteria. Complete blood count and biochemical profile showed no alteration and the test for feline leukemia virus (FeLV) and feline immunodeficiency virus (FIV) resulted negative. Histological changes were consistent with intra-epidermal pustular subcorneal with acantholysis dermatitis. An immunosuppressive dose of prednisolona was prescribed for 15 days. After this time, the crusted lesions were substituted by alopecia areas. Every 20 days the corticosteroid dose was reduced by half and after 90 days, the patient showed repilation in all regions previously affected during 545 days whithout treatment.

Discussion: Pemphigus foliaceus is usually an idiopathic disease but in some cases it may be induced by drugs and infectious or parasitic agents. Previous reports described that animals younger than 1 year-old and older than 17 year-old can be affected. However, the disease occurrence is rare in young cats. The age of onset of symptoms was early considering that the literature describes 5 years of age as an average for the starting of the disease. Pemphigus foliaceus is considered a pustular disease. However, pustule is rarely reported in cats in contrast with crusted lesions which are the most common clinical sign. The body regions affected were the same as reported in the literature with the addition of systemic signs as anorexia and lethargy. Fungal culture and parasitological examination should always be performed in cats with clinical evidence to discharge other agents. Diagnosis is made by skin histopathology in which acantholytic cells are the main characteristic. The importance of the differential diagnosis and skin biopsy regardless of age enabled the diagnosis and therapeutic success. It is suggested that Pemphigus foliaceus was of pharmacodermic etiology because of the age of the patient, a history of administration of unknown antimicrobial medication and the lack of recurrence of clinical manifestations after 545 days of the end of glucocorticoid treatment.
\end{abstract}

Keywords: pemphigus foliaceus, cat, pharmacodermia, crusted lesions.

Descritores: pênfigo foliáceo, gato, farmacodermia, lesões crostosas. 


\section{INTRODUÇÃ̃o}

O pênfigo foliáceo é a doença cutânea autoimune mais comum em cães e gatos. No entanto, ainda sim é considerada de ocorrência rara na clínica dermatológica felina $[5,15]$. É uma doença caracterizada pela produção de autoanticorpos contra um componente responsável pela adesão dos queratinócitos da camada superficial da epiderme, os desmossomos [2,4].

Felinos de qualquer raça ou sexo podem ser acometidos pela doença [14]. A idade média documentada para o ínicio da manifestação dos sinais clínicos é em torno de cinco anos, sendo que a faixa etária varia entre alguns meses até 17 anos de idade [8].

O diagnóstico padrão ouro é por meio da histopatologia cutânea, coletando material de diferentes locais, observando-se acantólise [1,4]. O tratamento mais utilizado para a doença envolve o uso de corticosteroides em doses imunossupressoras. Eventualmente podem ocorrer efeitos adversos à terapia, tais como desenvolvimento de diabetes, infecções na pele, no trato urinário [15], poliuria e polidipsia [17].

Em humanos, a acantólise também pode ocorrer, como uma forma de manifestação clínica de uma reação cutânea adversa a fármacos, como a administração de penicilina, entre outros exemplos [7]. Em medicina veterinária, foram relatados pênfigos foliáceos decorrentes de reações cutâneas adversas a fármacos em vários cães e pouquíssimos gatos, devido à administração de ampicilina, sulfonamida, amoxicilina, itraconazol, entre outros $[6,9,14]$.

O objetivo do presente relato é descrever os aspectos clínicos e evolução terapêutica de um caso de pênfigo foliáceo, possivelmente decorrente de uma reação cutânea adversa a fármaco, em um gato de oito meses de idade.

\section{CASO}

Foi atendido no Hospital de Clínicas Veterinárias da Universidade Federal do Rio Grande do Sul (HCV-UFRGS) um gato, macho, sem raça definida (SRD), oito meses de idade, com lesões crostosas na face. O paciente havia sido adotado de uma organização não governamental há dois meses e, desde então, apresentava espirros e dermatite pruriginosa na face. Fora anteriormente diagnosticado, em uma clínica local, com rinotraqueíte felina e dermatite herpética. Durante o tratamento para rinotraqueíte foram utilizados fármacos antimicrobiano e antinflamatório, porém o tutor não soube especificar quais. O paciente já havia sido vacinado e desverminado no local onde fora adotado.

No momento do atendimento, o felino apresentava lesões erosivas e crostosas em ponte nasal (Figura 1A), pavilhões auriculares (Figura 1B), região supraocular (Figura 1C), periungueais (Figura 1D) e alopecia na extremidade da cauda. Ao exame clínico geral todos os parâmetros encontravam-se dentro da normalidade para a espécie.

O resultado do exame de raspado parasitológico cutâneo e cultivo fúngico foi negativo. $\mathrm{O}$ exame de citologia das crostas, por meio de imprint, revelou bactérias de formato cocoide. O hemograma e exames bioquímicos estavam dentro da normalidade para a espécie. O teste de imunoensaio rápido para o diagnóstico do vírus da leucemia felina e vírus da imunodeficiência felina (Snap FIV/FeLV Combo Test $\left.{ }^{\circledR}\right)^{1}$ foi negativo.

Inicialmente foi prescrita amoxicilina com clavulanato (Agemox CL®) ${ }^{2}$ na dose de $20 \mathrm{mg} / \mathrm{kg}$, a cada $12 \mathrm{~h}$; prednisolona suspensão (Prelone $\AA)^{3}$ na dose antipruriginosa de $1 \mathrm{mg} / \mathrm{kg}$, uma vez ao dia, durante quatro dias, e após $0,5 \mathrm{mg} / \mathrm{kg}$, uma vez ao dia, durante cinco dias. Também foi utilizada solução de moxidectina e imidacloprida tópica (Advocate $\left.{ }^{\circledR}\right)^{4}$.

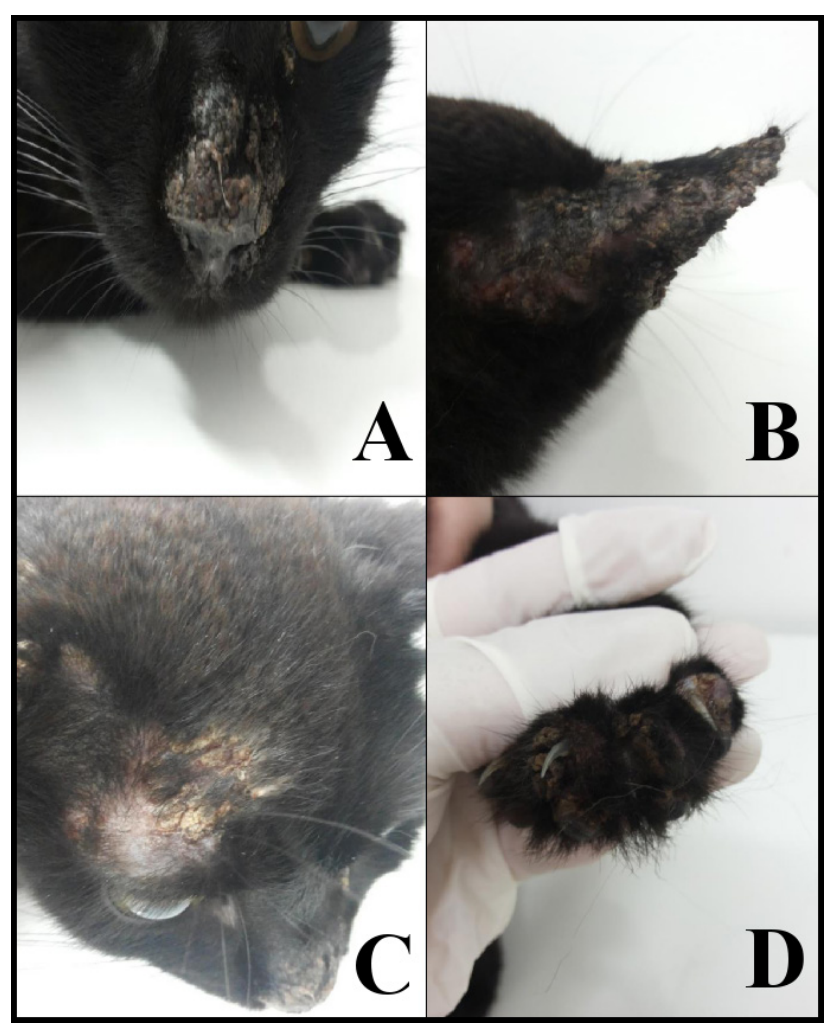

Figura 1. Felino, SRD, oito meses de idade, macho. A- Lesões crostosas no plano nasal dorsal. B- Lesões crostosas com exsudação purulenta localizadas na face externa do pavilhão auricular direito. C- Lesão crostosa em região supraocular direita. D- Paroníquea com exsudação purulenta no membro torácico esquerdo. 
Doze dias após a primeira consulta, as lesões haviam se estendido para o dorso da cabeça e face caudal dos membros pélvicos, o prurido havia se intensificado e o paciente estava apático e hiporéxico. Mediante a progressão da doença, realizou-se exame histológico. Áreas de lesões crostosas foram selecionadas para realização da biópsia incisional.

O exame histológico mostrou epiderme com hiperplasia regular, ortoqueratose compacta e em trançado de cesto e múltiplos focos de exocitose de neutrófilos com acantólise e formação de crostas queratoleucocitárias espessas nas quais se reconheciam queratinócitos acantolíticos. Na derme superficial e média existia edema e infiltrado inflamatório perivascular e perianexal misto com plasmócitos, linfócitos, neutrófilos e eosinófilos. Os folículos pilosos estavam ativos. Não se evidenciaram parasitas foliculares. As glândulas sebáceas e apócrinas não apresentaram alterações patológicas. As alterações foram compatíveis com dermatite intra-epidermal pustular subcorneal com acantólise. O padrão lesional histológico, unido ao histórico clínico, foi compatível com a suspeita clínica de pênfigo foliáceo.

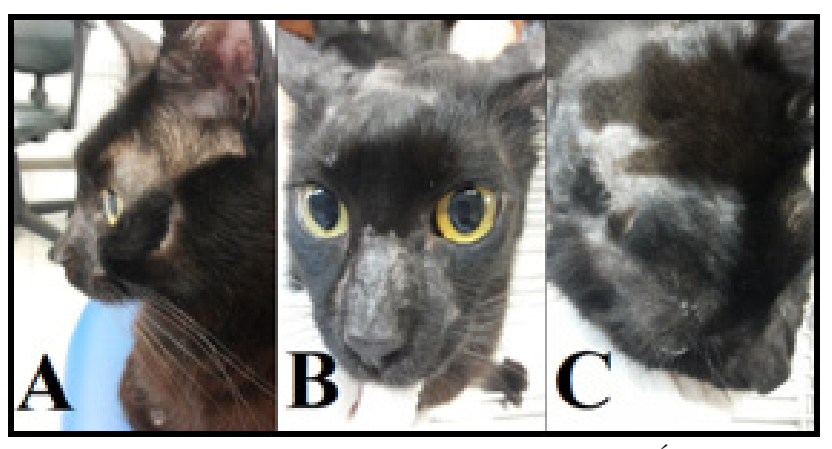

Figura 2. Felino, SRD, oito meses de idade, macho. A- Área alopécica em região supraocular esquerda. B- Área alopécica em plano nasal dorsal. C- Área alopécica na região frontal da cabeça.

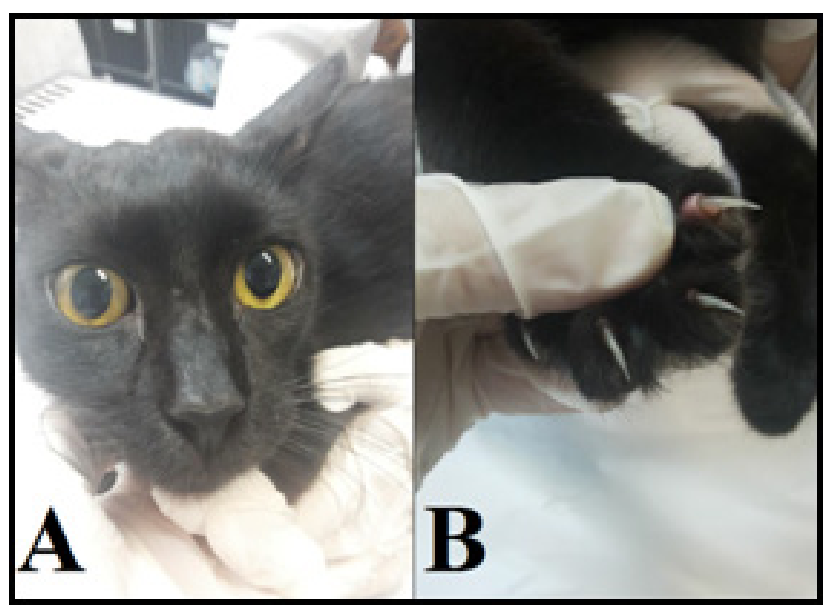

Figura 3. Felino, SRD, oito meses de idade, macho. A- Remissão das lesões da face. B- Remissão das lesões em leito ungueal.
Optou-se por fazer o tratamento com prednisolona suspensão, por via oral, na dose de $2 \mathrm{mg} / \mathrm{kg}$, a cada $12 \mathrm{~h}$, por 15 dias. Após esse período, o paciente não apresentava nenhuma lesão crostosa e as áreas anteriormente lesadas encontravam-se alopécicas (Figura 2).

Em seguida, foi reduzida a dose da prednisolona para $2 \mathrm{mg} / \mathrm{kg}$, a cada $24 \mathrm{~h}$, durante 20 dias. Após, a cada 20 dias a dose do fármaco foi reduzida pela metade, e ao chegar na dose de $0,25 \mathrm{mg} / \mathrm{kg}$ houve espaçamento da frequência para a cada $48 \mathrm{~h}$, finalizando com a suspensão da medicação. O tratamento durou 90 dias e, durante este período, foi realizada monitoração periódica por meio de exame clínico geral e exames hematológicos, os quais permaneceram dentro do padrão de normalidade. O paciente apresentou repilação em todas as regiões anteriormente afetadas ao final da terapêutica (Figura 3) e após 545 dias, não apresentou recidivas.

\section{DISCUSSÃO}

O pênfigo foliáceo geralmente é idiopático, mas alguns casos podem ser induzidos por fármacos e agentes infecciosos [4]. No caso relatado, o paciente recebeu diversos fármacos, como antimicrobiano e antinflamatório em função de possível rinotraqueíte infecciosa pregressa, além de vacinas e antiparasitários. Fármacos que possivelmente possam atuar como fatores desencadeadores incluem penicilinas, cefalosporinas, sulfonamida, enrofloxacina, metronidazol, itraconazol, cimetidina e algumas vacinas $[6,13,18]$. Neste caso não se pode afirmar que os fármacos ou até mesmo o agente viral possa ter participado como fator desencadeador, porém devido ao fato de o animal permanecer sem recidivas das lesões após 545 dias sem tratamento aventou-se a hipótese de pênfigo induzido por um reação adversa a fármaco.

Somado a isso, a idade do aparecimento dos sintomas foi mais precoce do que o descrito na literatura (média de cinco anos de idade) $[8,9,14,18]$, o que reforça a hipótese da etiologia farmacodérmica para o pênfigo neste caso.

O pênfigo foliáceo é considerado uma doença pustular, porém a pústula raramente é visualizada nos felinos, sendo as lesões crostosas o sinal clínico mais comum [8]. No presente caso, em nenhum momento foram visualizadas pústulas intactas, apenas crostas. Um estudo realizado na no Estado da Pensilvânia, Estados Unidos, com 57 gatos diagnosticados com pênfigo foliáceo, mostrou que na maioria dos casos as pústulas íntegras não foram encontradas [14], pois são extremamente transitórias [9]. 
As regiões do corpo acometidas, como face, cabeça, orelhas e leito ungueal, e os sinais sistêmicos apresentados pelo paciente como anorexia e letargia, corroboram com o descrito na literatura [13,15]. Inicialmente, não houve melhora dos sinais clínicos com a utilização do glicocorticoide. Atribuiu-se a isso à utilização da dose antinflamatória empregada, uma vez que para que ocorra remissão das lesões no pênfigo foliáceo é necessário o emprego de doses imunossupressoras [17], o que foi observado posteriormente à confirmação do diagnóstico histológico e ajuste na dose da prednisolona.

Vários autores correlacionam a monoterapia com glicocorticóide efetiva em gatos com pênfigo foliáceo $[10,14,16]$, assim como o paciente do presente relato, que teve melhora clínica apenas com a utilização de prednisolona. Um fator muito importante relacionado ao tratamento são os efeitos colaterais da terapia imunossupressiva com corticoide [15]. Entretanto, durante o tratamento o paciente não apresentou nenhum efeito colateral.

Em suma, sugere-se que o pênfigo foliáceo foi de etiologia farmacodérmica por causa da precocidade do surgimento da doença, do histórico de administração de medicação antimicrobiana desconhecida e da ausência de recidiva de manisfestações clínicas após 545 dias do término do tratamento com glicocorticoide.

\author{
MANUFACTURERS \\ ${ }^{1}$ Idexx Laboratories Ltd. Westbrook, ME, USA. \\ ${ }^{2}$ Agener União Ltda. São Paulo, SP, Brazil. \\ ${ }^{3}$ Aché Laboratórios Farmacêuticos SA. Guarulhos, SP, Brazil. \\ ${ }^{4}$ Bayer SA. São Paulo, SP, Brazil.
}

Declaration of interest. The authors report no conflicts of interest. The authors alone are responsible for the content and writing of the paper.

\section{REFERENCES}

1 Foster A.P. 2006. Pele. In: Chandler E.A., Gaskell C.J. \& Gaskell R.M (Eds.). Clínica e Terapêutica em Felinos. 3.ed. São Paulo: Roca, pp.81-85.

2 Gross T.L., Ihrke P.L., Walder E.J. \& Affolter V.K. 2009. Doenças pustulares da epiderme. In: Doenças de Pele do Cão e do Gato: Diagnóstico Clínico e Histopatológico. 2.ed. São Paulo: Roca, pp.13-17.

3 Harvey R.G. \& McKeever P.J. 2004. Pênfigo foliáceo. In: Manual Colorido de dermatologia do cão e do gato: Diagnóstico e Tratamento. Rio de Janeiro: Revinter, pp.113-115.

4 Hnilica K.A. \& Patterson A.P. 2017. Autoimmune and Immune-Mediated Skin Disorders. In: Small Animal Dermatology: a color atlas and therapeutic guide. 4th edn. St. Louis: Elsevier, pp.245-301.

5 Jark P.C., Estanislau C.A., Rondelli M.C.H., Fabris V.E., Tinucci-Costa M., Lourenço M.L.G. \& Machado L.H.A. 2014. Pênfigo foliáceo em um felino: relato de caso. Veterinária e Zootecnia. 21(4): 543-549.

6 Little S.E. 2012. Dermatology. In: The Cat: Clinical Medicine and Management. St. Louis: Elsevier, pp.371-424.

7 Mason K.V. \& Day M.J. 1987. A pemphigus foliaceus-like eruption associated with the use of ampicillin in a cat. Australian Veterinary Journal. 64(7): 223-224.

8 Miller W.H., Griffin C.E. \& Campbell K.L. 2013. Autoimmune and immune-mediated dermatoses. In: Muller \& Kirk's Small Animal Dermatology. 7th edn. St. Louis: Elsevier, pp.432-500.

9 Olivry T. 2006. A review of autoimmune skin diseases in domestic animals: I - Superficial pemphigus. Journal compilation European Society of Veterinary Dermatology. 17: 291-305.

10 Olivry T. \& Chan L.S. 2001. Autoimmune blistering dermatoses in domestic animals. Clinics in Dermatology. 19: 750-760.

11 Olivry T. \& Linder K.E. 2009. Dermatoses affecting desmosomes in animals: a mechanistic review of acantholytic blistering skin diseases. Veterinary Dermatology. 20: 313-326.

12 Pereira A.V., Plischke K.M., Dahia M.C. \& Silva P.T.D. 2011. Pênfigo Foliáceo em Felinos: relato de três casos. Medvep Dermato - Revista de Educação Continuada em Dermatologia e Alergologia Veterinária. 1(1): 48-55.

13 Peterson A. \& McKay L. 2010. Crusty Cats: feline pemphigus foliaceus. Compendium Continuing Education for Veterinarians. 32(5): 1-4.

14 Preziosi D.E., Goldschimidt M.H., Greek J.S., Jeffers J.G., Shanley K.S., Drobatz K. \& Mauldin E.A. 2003. Feline pemphigus foliaceus: a retrospective analysis of 57 cases. Veterinary Dermatology. 14: 313-321.

15 Rees C.A. 2011. Pemphigus Foliaceous. In: Norsworthy G.D. (Ed). The Feline Patient. 4th edn. Ames: Blackwell, pp.392-393. 16 Rosenkrantz W.S. 2004. Pemphigus: current therapy. Veterinary Dermatology. 15: 90-98. 
C.G. Lupion, E.H.M. Pino, E. Silveira, C.R. Stefanello, L.T. Baretta \& D.G. Gerardi. 2017. Pênfigo foliáceo em um gato de oito meses de idade: possível reação cutânea adversa a fármacos?

17 Simpson D.L. \& Burton G.G. 2013. Use of prednisolone as monotherapy in the treatment of feline pemphigus foliaceus: a retrospective study of 37 cats. Veterinary Dermatology. 24: 598-e144.

18 Talhada D.F.R.M. 2011. Contribution to the study of Feline Pemphigus Foliaceus. 61f. Vila Real, Portugal. Dissertação (Mestrado em Ciências Veterinárias) - Mestrado Integrado em Medicina Veterinária, Universidade de Trás-os-Montes e Alto-Douro. 